\title{
Syndactyly-telecanthus-anogenital and renal malformations syndrome
}

INSERM

\section{Source}

INSERM. (1999). Orphanet: an online rare disease and orphan drug data base. Syndactylytelecanthus-anogenital and renal malformations syndrome. ORPHA:140952

This syndrome is characterised by the association of toe syndactyly, facial dysmorphism including telecanthus (abnormal distance between the eyes) and a broad nasal tip, urogenital malformations and anal atresia. 